\title{
Cullin 1 is not associated with late-onset preeclampsia
}

\author{
Tjam Diana Samara****, Isabella Kurnia Liem***, Ani Retno Prijanti ${ }^{\dagger}$, and Andrijono
}

\begin{abstract}
BACKGROUND
Late-onset preeclampsia (PE) is preeclampsia occurring after 34 weeks of gestational age or later. Cullin 1 (CUL1), a proangiogenic protein, is expressed in the placenta, where an imbalance between proangiogenic and antiangiogenic proteins during gestation can cause disturbance of trophoblast invasion. This defect results in vascular ischemia that may produce preeclampsia. The objective of this study was to determine the correlation between CUL1 as proangiogenic factor and late-onset preeclampsia.
\end{abstract}

\section{METHODS}

This study was of analytical observational cross-sectional design and involved 44 preeclampsia patients with $\geq 34$ weeks of gestational age (lateonset PE). The CUL1 level in the subjects' sera, taken before they gave birth, and in homogenates of their placenta, obtained per vaginam or by cesarean section, were examined by the ELISA technique. Statistical analysis was performed with the Spearman correlation test with significant $p$ value of $<0.05$.

\section{RESULTS}

Median maternal age was 31 years and median gestational age was 37 weeks. Median serum CUL1 was $41.78 \mathrm{pg} / \mathrm{mL}$ and median placental homogenate CUL1 was $32.24 \mathrm{pg}$ per milligram of total placental tissue protein. There was no significant correlation between serum CUL1 level and late-onset preeclampsia $(\mathrm{r}=-0.281 ; \mathrm{p}=0.065)$. There was also no significant correlation between placental CUL1 level and late-onset preeclampsia $(\mathrm{r}=-0.166 ; \mathrm{p}=0.281)$.

\section{CONCLUSION}

Serum CUL1 and placental CUL1 were not correlated with late-onset preeclampsia. However, this study indicated that low serum CUL1 tends to prolong gestational age in preeclampsia.

Keywords: CUL1, proangiogenic, serum, placenta, late-onset, preeclampsia

\author{
*Biomedical Sciences Doctoral Program, \\ Faculty of Medicine, \\ Universitas Indonesia \\ **Department of Anatomy, \\ Faculty of Medicine, \\ Trisakti University \\ ***Department of Anatomy, \\ Faculty of Medicine, \\ Universitas Indonesia \\ Department of Biochemistry and \\ Molecular Biology, \\ Faculty of Medicine, \\ Universitas Indonesia \\ Department of Obstetrics and \\ Gynecology, Faculty of Medicine, \\ Universitas Indonesia

\section{Correspondence \\ Tjam Diana Samara \\ Department of Anatomy, \\ Faculty of Medicine, \\ Trisakti University \\ Jl. Kyai Tapa No.260-Grogol Jakarta \\ Phone: +6221 5672731 ext.2106 \\ E-mail:dianasamara2@gmail.com \\ Date of first submission, September 26, 2018 \\ Date of final revised submission, \\ January 29, 2019 \\ Date of acceptance, January 30, 2019}

This open access article is distributed under a Creative Commons AttributionNon Commercial-Share Alike 4.0 International License

Cite this article as: Samara TD, Liem IK, Prijanti AR, et al. Cullin 1 is not associated with late-onset preeclampsia Univ Med 2019;38:4-9. doi: 10.18051/UnivMed.2018.v38.4-9 


\section{INTRODUCTION}

Preeclampsia (PE) is the occurrence of hypertension with proteinuria at a gestational age of more than 20 weeks or immediately after delivery. ${ }^{(1)}$ Preeclampsia is the main cause of morbidity and mortality, both in mother and fetus. The global incidence of PE is around 2$8 \%$ of all pregnancies, with a maternal mortality rate of around $10 \%-15 \%$. $^{(2)}$

The most recent PE classification is based on the categories early-onset and late-onset. Early-onset PE ( $<34$ weeks) is generally associated with abnormal uterine arterial Doppler findings, fetal growth restriction (FGR), and adverse outcomes to both mother and newborn. ${ }^{(3,4)}$ On the other hand, late-onset PE ( $\geq 34$ weeks) is mostly associated with a normal or slightly increased uterine resistance index, a low rate of fetal involvement, and has a more favorable perinatal outcome. ${ }^{(3,5)}$

There are several hypotheses on PE etiology, such as genetic factors, immunological disorders, paternal factors, endothelial dysfunction, and placental ischemia due to trophoblast invasion of the spiral arteries. Placental ischemia causes various problems in pregnant women, such as hypertension and proteinuria and abnormal fetal growth. The ischemia is due to functional imbalance between proangiogenic and antiangiogenic factors, resulting in trophoblast invasion, and ultimately causing reduced perfusion of the fetoplacental unit. ${ }^{(6)}$ The distribution of angiogenic factors depends on gestational age. ${ }^{(7)}$ At the onset of a normal pregnancy, the proangiogenic factors are predominant, whereas at the end of pregnancy, the antiangiogenic factors take over, being required for delivery. The imbalance of angiogenic factors in PE results in a shallow cytotrophoblast endovascular invasion and inadequate vascular formation of the uterine vessels as compared with a normal pregnancy. ${ }^{(6)}$ As a result of the disturbed trophoblast invasion, there is no dilation of the spiral arteries, so causing increased vascular resistance, leading to the signs of hypertension and proteinuria in PE. ${ }^{(8)}$

Examples of proangiogenic factors that play a role in trophoblast invasion are vascular endothelial growth factor (VEGF), ${ }^{(8)}$ placental growth factor (PlGF), ${ }^{(8)}$ transforming growth factor-beta1 (TGF- $\beta 1){ }^{(9)}$ insulin-like growth factor 2 mRNA binding protein 3 (IGF2BP3), ${ }^{(10)}$ matrix metalloproteinase (MMP), ${ }^{(11)}$ Cullin 1 (CUL1), ${ }^{(12)}$ Cullin 3 (CUL3), ${ }^{(13)}$ Cullin 4A (CUL4A ), ${ }^{(14,15)}$ and Cullin 7 (CUL7). ${ }^{(16)}$

With regard to the association between angiogenic factors and late-onset PE, Soto et al. ${ }^{(17)}$ found an imbalance between proangiogenic and antiangiogenic factors in patients with lateonset PE, with or without placental lesions and consistent with maternal under perfusion. In contrast, Schaarschmidt et al. ${ }^{(18)}$ found increased antiangiogenic factors in early-onset $\mathrm{PE}$, with sFLt-1 being higher than in late-onset PE, and a sharp decline in proangiogenic PIGF levels as compared with late-onset $\mathrm{PE}$, and yielding a higher soluble fms-like tyrosine kinase-1 (sFlt-1)/PlGF ratio as compared with late-onset PE. Meanwhile, Escudero et al. ${ }^{(19)}$ found increases in placental angiogenic factors in both early and late-onset PE.

CUL1 is a proangiogenic protein in humans from the cullin gene family and is an essential component of the SKP1-CUL1-F-box protein (SCF) E3 ubiquitin ligase complex. CUL1 consists of 776 amino acids and has a molecular weight of 89679 Daltons. The protein is found in the cytosol and nucleus, and in small amounts in the cytoskeleton, and is localized in chromosome 7q36.1. ${ }^{(20,21)}$ CUL1 belongs to the group of cullinbased ubiquitin ligases, that are a subtype of the RING-type ubiquitin ligases and form multisubunit complexes. ${ }^{(22)}$

CUL1 plays an important role in protein degradation and ubiquitination, and mediates protein ubiquitination for involvement in cell cycle progression, signal transduction, and transcription. In the SCF complex, CUL1 serves as a rigid scaffold for assembling of the SKP1 and RBX1 subunits. ${ }^{(23)}$ Knockout of CUL1 in mice produces 
early embryonic lethality. Therefore CUL1 plays an essential role in embryonic development and contributes significantly to normal and malignant cellular processes. ${ }^{(24)}$ There is only a single study on CUL1 in connection with PE, namely the study of Zhang et al.(12) showing that CUL1 stimulates human trophoblast invasion and dysregulation of CUL1 expression in patients with PE.

To date there is no information about studies on the association between CUL1 concentration and pregnancies with late-onset PE. The aim of this study was to determine the association between CUL1 concentration and gestational age in late-onset PE.

\section{METHODS}

\section{Design of the study}

This study was of analytical observational cross-sectional design and was conducted in Cipto Mangunkusumo Hospital (RSCM) and Budi Kemuliaan Hospital, Jakarta, Indonesia from April 2017 - January 2018.

\section{Subjects of the study}

The study sample comprised women with late-onset $\mathrm{PE}$ and gestational age of $\geq 34$ weeks, who were more than 15 years old, and agreed to participate in this study by signing a declaration of informed consent. The exclusion criteria of the study subjects were diabetes mellitus and chronic renal failure. Venous blood samples and placentas were collected to a total of 44 samples from women with $\mathrm{PE}$ at gestational ages of $\geq 34$ weeks who were delivered per vaginam or by cesarean section.

$\mathrm{PE}$ is defined and classified based on the criteria recommended by the American College of Obstetrics and Gynecologists (ACOG) in 2013, namely hypertension appearing and developimg after 20 weeks of pregnancy (systolic pressure $\geq 140 \mathrm{mmHg}$ and/or diastolic pressure $\geq 90$ $\mathrm{mmHg}$ ), and proteinuria ( $\geq 300 \mathrm{mg}$ in 24 -hr urine) or with protein-positive $1(+)$ reading from midstream urine. Preeclampsia may be without proteinuria but must have one of the following symptoms: thrombocytopenia $(<100.000 /$ microliter), renal insufficiency (serum creatinine $>1.1 \mathrm{mg} / \mathrm{dL}$ ), abnormal liver function (two-fold increases in transaminases as compared to normal), pulmonary edema, and cerebral or visual disturbances. ${ }^{(1)}$

\section{Serum CUL1 measurement}

A volume of $5 \mathrm{~mL}$ of maternal blood was collected less than 24 hours before delivery and subsequently processed into serum by centrifugation at 3500 RPM for 10 minutes. The serum was collected and stored at a temperature of $-80^{\circ} \mathrm{C}$. After the required number of blood samples was reached, the CUL1 level was determined (MyBiosource MBS921353) by means of the ELISA technique according to the protocol from MyBiosource.

\section{Placental CUL1 measurement}

The placental cotyledons (maternal side) were cut up into cubes of $0.5 \times 0.5 \times 0.5 \mathrm{~cm}$ immediately after vaginal delivery or delivery by cesarean section. A total of $100 \mathrm{mg}$ of placental tissue was washed in PBS and then processed to obtain a homogenate in $1 \mathrm{~mL}$ of PBS and stored at $-80^{\circ} \mathrm{C}$. After the required number of placental samples was reached, the CUL1 level was determined (MyBiosource MBS921353) by means of the ELISA technique according to the protocol from MyBiosource.

\section{Ethical clearance}

This study obtained ethical clearance from the Health Research Ethics Committee, Faculty of Medicine, Universitas Indonesia, under No. 34/ UN2.F1/ETIK/2017.

\section{Statistical analysis}

The normality of the data was determined using the Kolmogorov-Smirnov test. Since the data turned out to be non-normally distributed, the non-parametric Spearman correlation test was used to determine the association of serum CUL1 and placental CUL1 levels with late-onset PE. A p-value of $<0.05$ was considered significant. 
Table 1. Distribution of features characteristics of the subjects

\begin{tabular}{lcc}
\hline Variable & n & Median \\
\hline Maternal age (years) & 44 & 31 \\
Gestational age (weeks) & 44 & 37 \\
Systolic pressure (mmHg) & 43 & 160 \\
Diastolic pressure (mmHg) & 43 & 100 \\
Urinary protein (qualitative) & 32 & 2 \\
Serum CUL1 (pg/mL) & 44 & 41.78 \\
Placental CUL 1 (pg/mg) & 44 & 32.24 \\
Placental protein $(\mathrm{mg} / \mathrm{mL})$ & 44 & 9.83 \\
\hline
\end{tabular}

\section{RESULTS}

Table 1 shows that the median age was 31 years and the median gestational age 37 weeks. Median systolic blood pressure was $160 \mathrm{mmHg}$ and median diastolic blood pressure $100 \mathrm{mmHg}$. Median qualitative urinary protein reading was 2.

Median serum CUL1 was $41.78 \mathrm{pg} / \mathrm{mL}$ and median placental homogenate CUL1 was 32.24 $\mathrm{pg} / \mathrm{mg}$ of placental tissue protein. Median total placental tissue protein was $9.82 \mathrm{mg} / \mathrm{mL}$. Placental CUL1 level was calculated from homogenate CUL1 divided by total placental tissue protein, to obtain pure CUL1 protein per total placental tissue protein.

In Table 2 it is apparent that there was no significant association between PE maternal serum CUL1 concentration and gestational age of $\geq 34$ weeks $(r=-0.281 ; p=0.065)$. Similarly, there was no significant association between placental CUL1 concentration and gestational age of $\geq 34$ weeks ( $r=-0.166 ; p=0.281$ ).

\section{DISCUSSION}

Late-onset PE is PE occurring at 34 weeks of pregnancy or later. There are few studies on late-onset $\mathrm{PE}$ in connection with angiogenic factors, including studies on CUL1 as proangiogenic factor in pregnancy. There are indeed several studies on CUL1, but not in connection with PE in pregnancy. The study conducted by Choudhury et al. ${ }^{(25)}$ showed that CUL1 is part of the SCF complex that mediates ubiquitin-dependent cyclin G1 degradation and cyclin-dependent kinase inhibitors. The SCF complex consists of Skp, Cullin, and the F-box containing complex. Staropoli et al. ${ }^{(26)}$ proved that the F-box and WD40 domain protein 7 (FBXW7) and CUL1 are located inside a distinct ubiquitin ligase complex that targets its ligase activity on cyclin $E$ in the regulation of neuronal apoptosis. Deficiency of the SCF-Skp2 E3 ligase complex results in breast cancer metastases, impaired RhoA expression, cell migration, and cell invasion. ${ }^{(27)}$

Our study comprises 44 samples from PE study subjects with gestational age of $\geq 34$ weeks. According to the categories of early- and late-onset PE, a gestational age of $\geq 34$ weeks belongs to the late-onset category. ${ }^{(4)}$ Theoretically, in a normal pregnancy, the later the gestational age, the lower the concentrations of proangiogenic proteins, followed by increased concentrations of antiangiogenic proteins. In PE the conditions are reversed, where the antiangiogenic concentrations are increased at the onset of pregnancy. ${ }^{(6)}$ However, there are as yet no further insights in connection with the changes in proangiogenic protein concentrations in patients with $\mathrm{PE}$. Fu et al. found another member of the cullin family, i.e. CUL7, that in the form of the CUL7 E3 ligase increases trophoblast migration and induces trophoblast epithelial-mesenchymal transition (EMT) through upregulated expression of ZEB1 and SLUG, two repressors of E-cadherin transcription. ${ }^{(16)}$ Zhang et al. ${ }^{(13)}$ in their study

Table 2. Association between CUL1 concentration and gestational age of $\geq 34$ weeks

\begin{tabular}{lcc}
\hline \multicolumn{1}{c}{ Variables } & r & p-value \\
\hline Serum CUL1 - gestational age of $\geq 34$ weeks & -0.281 & 0.065 \\
Homogenate CUL1 - gestational age of $\geq 34$ weeks & -0.166 & 0.281 \\
\hline
\end{tabular}

$\mathrm{r}=$ Spearman correlation coefficient 
on CUL3 found that CUL3 plays a role in increased trophoblast invasion and migration and the occurrence of CUL3 dysregulation may cause PE. However, there is just a single study on CUL1 in connection with trophoblast invasion in PE. Zhang et al. ${ }^{(12)}$ found by means of realtime q PCR and western blot assays, that CUL1 expression significantly decreases in primary human placental cytotrophoblast during syncytialization. CUL1 expression was significantly lower in placental villi in preeclampsia, as compared with equivalent placental controls. These investigators also found that CUL1 plays a role in enabling trophoblast invasion.

The study subjects used by Zhang et al. were PE patients aged 23-35 years with mature pregnancies (36-40 weeks). In contrast, our study used study subjects of age 20-43 years and did not find any association between PE gestational age of $\geq 34$ weeks and CUL1 concentration, both in serum and placental homogenate. Since Zhang et al. ${ }^{(12)}$ did not determine the serum CUL1 concentration in patients with $\mathrm{PE}$, there can be no comparison of serum CUL1 concentration in patients with PE with those of controls. The theory expressed by Tomimatsu et al. ${ }^{(6)}$ does not mention decreased proangiogenic protein concentration as one of the causes of PE, but that imbalances in angiogenic factors are one of the causes of $\mathrm{PE}$, either through early or excessive antiangiogenic protein production. Further studies are needed to determine the extent of proangiogenic factor involvement in $\mathrm{PE}$ angiogenic factor imbalance.

Our study did not include the gestational age of $<34$ weeks, so that it is not possible to compare the changes in CUL1 concentration between late-onset ( $\geq 34$ weeks) and early-onset pregnancy. In our study no normal pregnancies were used, which is one of the limitations of this study. The knowledge about the association of CUL1 concentration with gestational age is required to allow the use of the CUL1 concentration as a marker for monitoring $\mathrm{PE}$ development in connection with gestational age.

\section{CONCLUSIONS}

The serum CUL1 concentration as well as the placental CUL1 concentration are not associated with PE gestational age of $\geq 34$ weeks. Further studies are needed using PE gestational age of $\leq 34$ weeks to determine the presence or absence of differences in CUL1 concentrations between these differing pregnancy groups. These studies are needed to determine the extent of the role of angiogenic factors, in this case CUL1, in connection with PE development by gestational age.

\section{CONFLICT OF INTEREST}

Competing interest: no relevant disclosures.

\section{ACKNOWLEDGMENT}

This study was funded by the Directorate of Research and Community Service, Directorate General of Research and Development Reinforcement, Indonesian Ministry of Research, Technology, and Higher Education (No: 011/KM/ /BAP/I/PNT/2018).

\section{CONTRIBUTORS}

TDS contributed to compilation of the subject matter, writing of the manuscript drafts, data collection, and data analysis. IKL contributed to manuscript finalization. ARP contributed to the study concept and design. A contributed to manuscript revision. All authors have read and approved the final manuscript.

\section{REFERENCES}

1. Woelkers D, Barton J, von Dadelszen P, et al. [71-OR]: the revised 2013 ACOG definitions of hypertensive disorders of pregnancy significantly increase the diagnostic prevalence of preeclampsia. Pregnancy Hypertens 2015;5:38. doi: 10.1016/j.preghy.2014.10.075.

2. Eiland E, Nzerue C, Faulkner M. Preeclampsia 2012. J Pregnancy 2012, Article ID 586578, 7 pages. doi: 10.1155/2012/586578 2012. 
3. Valensise H, Vasapollo B, Gagliardi G, et al. Early and late preeclampsia: two different maternal hemodynamic states in the latent phase of the disease. Hypertension 2008;52:873-80. doi: 10.1161/HYPERTENSIONAHA.108.117358.

4. Ness RB, Sibai BM. Shared and disparate components of the pathophysiologies of fetal growth restriction and preeclampsia. Am J Obstet Gynecol 2006;195:40-9.

5. Sibai B, Dekker G, Kupferminc M. Pre-eclampsia. Lancet 2005;365:785-99.

6. Tomimatsu T, Mimura K, Endo M, et al. Pathophysiology of preeclampsia: an angiogenic imbalance and long-lasting systemic vascular dysfunction. Hypertens Res 2017;40:305-10. doi: 10.1038/hr.2016.152.

7. Vaswani K, Hum MWC, Chan HW, et al. The effect of gestational age on angiogenic gene expression in the rat placenta. PLoS One 2013;8: e83762. doi: 10.1371/journal.pone.0083762.

8. Romero R, Chaiworapongsa T. Preeclampsia: a link between trophoblast dysregulation and an antiangiogenic state. J Clin Invest 2013;123:27757. doi: 10.1172/JCI70431.

9. Powe CE, Levine RJ, Karumanchi SA. Preeclampsia, a disease of the maternal endothelium: the role of antiangiogenic factors and implications for later cardiovascular disease. Circulation 2011;123:2856-69. doi: 10.1161/ CIRCULATIONAHA.109.853127.

10. Li W, D Liu D, Chang W, et al. Role of IGF2BP3 in trophoblast cell invasion and migration. Cell Death Dis 2014;5:e1025. doi: 10.1038/cddis.2013. 545.

11. Zhu JY, Pang ZJ, Yu YH. Regulation of trophoblast invasion: the role of matrix metalloproteinases. Rev Obstet Gynecol 2012;5: e137-43. doi: 10.3909/riog0196.

12. Zhang Q, Chen Q, Lu X, et al. CUL1 promotes trophoblast cell invasion at the maternal-fetal interface. Cell Death Dis 2013;4:e502. doi: 10.1038/cddis.2013.1.

13. Zhang Q, Yu S, Huang X, et al. New insights into the function of Cullin 3 in trophoblast invasion and migration. Reproduction 2015;150:139-49. doi: 10.1530/REP-15-0126.

14. Zhuang T, Fu J, Zhang Q, et al. CUL4A is expressed in human placenta and involved in trophoblast cell invasion. Int J Clin Exp Pathol 2016;9:1351-9.

15. Tan D, Liang H, Cao K, et al. CUL4A enhances human trophoblast migration and is associated with pre-eclampsia. Int J Clin Exp Pathol 2017; 10: 10544-51.
16. Fu J, Lv X, Lin H, et al. Ubiquitin ligase cullin 7 induces epithelial-mesenchymal transition in human choriocarcinoma cells. J Biol Chem 2010;285:10870-9. doi: 10.1074/jbc.M109.004200.

17. Soto E, Romero R, Kusanovic JP, et al. Late-onset preeclampsia is associated with an imbalance of angiogenic and anti-angiogenic factors in patients with and without placental lesions consistent with maternal underperfusion. J Matern Fetal Neonatal Med 2012;25:498-507. doi: 10.3109/14767058.2011.591461.

18. Schaarschmidt W, Rana S, Stepan H. The course of angiogenic factors in early- vs. late-onset preeclampsia and HELLP syndrome. J Perinat Med 2013;41:511-6. doi:10.1515/jpm-2012-0248.

19. Escudero C, Celis C, Saez T, et al. Increased placental angiogenesis in late and early onset pre-eclampsia is associated with differential activation of vascular endothelial growth factor receptor 2. Placenta 2014;35:207-15. doi: 10.1016/ j.placenta.2014.01.007.

20. Sarikas A, Hartmann T, Pan ZQ. The cullin protein family. Genome Biol 2011; 12:220. doi: 10.1186/gb-2011-12-4-220.

21. GeneCards. CUL1 Gene. CUL1 (Cullin 1) is a Protein Coding gene. Available at: https:/www. genecards.org/cgi-bin/carddisp.pl?gene=CUL1 . Accessed Octobet 12,2018.

22. Lydeard JR, Schulman BA, Harper JW. Building and remodelling Cullin-RING E3 ubiquitin ligases. EMBO Rep 2013;14:1050-61. doi: 10.1038/embor.2013.173.

23. Li Y, Hao B. Structural basis of dimerizationdependent ubiquitination by the $\mathrm{SCF}^{\mathrm{Fbx} 4}$ ubiquitin ligase. J Biol Chem 2010;285:13896 906. doi: 10.1074/jbc.M110.111518.

24. Lee J, Zhou P. Cullins and cancer. Genes Cancer 2010;1:690-9. doi: 10.1177/1947601910382899.

25. Choudhury R, Bonacci T, Wang X, et al. The E3 ubiquitin ligase SCF (Cyclin F) transmits AKT signaling to the cell cycle machinery. Cell Rep 2017; 20: 3212-22. doi: 10.1016/j.celrep.2017. 08.099 .

26. Staropoli JF, McDermott C, Martinat C, et al. Parkin is a component of an SCF-like ubiquitin ligase complex and protects postmitotic neurons from kainate excitotoxicity. Neuron 2003;37:73549.

27. Chan CH, Lee SW, Li CF, et al. Deciphering the transcriptional complex critical for RhoA gene expression and cancer metastasis. Nat Cell Biol 2010;12:457-67. doi: 10.1038/ncb2047. 